\title{
Blackbody Infrared Radiative Dissociation of Nonspecific Protein-Carbohydrate Complexes Produced by Nanoelectrospray Ionization: The Nature of the Noncovalent Interactions
}

\author{
Weijie Wang, Elena N. Kitova, Jiangxiao Sun, and John S. Klassen \\ Department of Chemistry, University of Alberta, Edmonton, Alberta, Canada
}

\begin{abstract}
Gas-phase thermal dissociation experiments, implemented with blackbody infrared radiative dissociation (BIRD) and Fourier transform ion cyclotron resonance mass spectrometry, have been performed on a series of protonated and deprotonated 1:1 and protonated 1:2 proteincarbohydrate complexes formed by nonspecific interactions during the nanoflow electrospray (nanoES) ionization process. Nonspecific interactions between the proteins bovine carbonic anhydrase II (CA), bovine ubiquitin (Ubq), and bovine pancreatic trypsin inhibitor and several carbohydrates, ranging in size from mono- to tetrasaccharides, have been investigated. Over the range of temperatures studied $\left(60-190{ }^{\circ} \mathrm{C}\right)$, BIRD of the protonated and deprotonated complexes proceeds exclusively by the loss of the carbohydrate in its neutral form. The rates of dissociation of the 1:1 complexes containing a mono- or disaccharide decrease with reaction time, suggesting the presence of two or more kinetically distinct structures produced during nanoES or by gas-phase processes. In contrast, the 1:1 complexes of the tri- and tetrasaccharides exhibit simple first-order dissociation kinetics, a result that, on its own, is suggestive of a single preferred carbohydrate binding site or multiple equivalent sites in the gas phase. A comparative analysis of the dissociation kinetics measured for protonated 1:1 and 1:2 complexes of Ubq with $\alpha \operatorname{Tal}[\alpha \mathrm{Abe}] \alpha \mathrm{Man}$ further supports the presence of a single preferred binding site. However, a similar analysis performed on the complexes of CA and $\alpha \operatorname{Tal}[\alpha$ Abe $] \alpha$ Man suggests that equivalent but dependent carbohydrate binding sites exist in the gas phase. Analysis of the Arrhenius activation parameters $\left(E_{a}\right.$ and $\left.A\right)$ determined for the dissociation of 1:1 complexes of CA with structurally related trisaccharides provides evidence that neutral intermolecular hydrogen bonds contribute, at least in part, to the stability of the gaseous complexes. Surprisingly, the $E_{a}$ values for the complexes of the same charge state are not sensitive to the structure (primary or higher order) of the protein, suggesting that the carbohydrates are able to form energetically equivalent interactions with the various functional groups presented by the protein. For a given protein-carbohydrate complex, the dissociation $E_{a}$ is sensitive to charge state, initially increasing and then decreasing with increasing charge. It is proposed that both ionic and neutral hydrogen bonds stabilize the nonspecific protein-carbohydrate complexes in the gas phase and that the relative contribution of the neutral and ionic interactions is strongly influenced by the charge state of the complex, with neutral interactions dominating at low charge states and ionic interactions dominating at high charge states. (J Am Soc Mass Spectrom 2005, 16, 1583-1594) (c) 2005 American Society for Mass Spectrometry
\end{abstract}

$\mathrm{T}$ The application of mass spectrometry to biochemical problems has been revolutionized by the development of the electrospray (ES) ionization technique, in which dissolved species, which may be neutral or carry a net charge, are transferred into the gas phase in an ionized form. An important feature of the ES technique is the ability to transfer intact nonco-

Published online August 8, 2005

Address reprint requests to Dr. J. S. Klassen, Department of Chemistry, University of Alberta, Edmonton, Alberta, Canada T6G 2G2. E-mail: john.klassen@ualberta.ca valently bound biological complexes, such as proteinreceptor, enzyme-substrate, and multiprotein complexes, from buffered aqueous solutions to the gas phase. As a result, ES/mass spectrometry (MS) has become a powerful tool for detecting specific biomolecular complexes in solution and is increasingly used to quantify their binding stoichiometry and affinity [1-6]. Although solution-specific biomolecular complexes often are detected easily by ES/MS, it is not clear to what extent the structures of the gaseous complexes and, in particular, the intermolecular interactions resemble those present in solution. Nonspecific interactions, that 
is, interactions not present in solution and which form during or after the ES process, have been shown to contribute significantly to the stability of some specific complexes in the gas phase [7-11]. The formation of nonspecific interactions during the ES process may be beneficial and, perhaps, even necessary to the survival of certain biological complexes, in particular those stabilized predominantly by hydrophobic interactions [7]. In addition to the formation of nonspecific interactions within specific complexes, nonspecific interactions between biomolecules that do not bind in solution and between biomolecules and small neutral molecules or ions present in solution also may occur during the ES process. Although the mechanism of their formation is not fully understood, nonspecific complexes involving macromolecules, such as proteins, are believed to arise in charged droplets, containing multiple analyte molecules, as the solvent is lost [12], that is, the charge residue ES model. The gaseous complexes produced by the nonspecific interaction may be sufficiently stable (kinetically) that they survive the ion source and are detected by mass spectrometry.

Although the tendency of biological molecules to engage in nonspecific intermolecular interactions during the ES process, particularly at elevated analyte concentrations, is widely recognized, little is known about the nature of the interactions responsible for their stability. A greater understanding of the nonspecific complexes may facilitate the development of new strategies to reduce or minimize the appearance of these complexes in ES/MS spectra. Identifying and quantifying the intermolecular interactions responsible for stabilizing nonspecific complexes also may reveal new insights into the structural changes that accompany the desolvation of biological complexes during ES and, thereby, aid the in the development of direct ES/MSbased techniques to characterize the structures of biomolecular complexes in solution. Gas-phase studies of nonspecific interactions between proteins and small polyfunctional molecules, such as carbohydrates and amino acids, are also relevant to ongoing efforts to elucidate the mechanisms by which these molecules are able to stabilize proteins and biologicals in low-humidity environments [13, 14].

To develop a greater understanding of the factors responsible for the formation nonspecific complexes between proteins and other polyfunctional molecules, including small biopolymers, and the forces that stabilize the gaseous complexes, our laboratory has undertaken a comprehensive investigation of nonspecific protein-carbohydrate complexes originating from nonspecific interactions formed by nanoflow ES (nanoES). In the first of a series of studies [15], the kinetic stability and the energetic stability (i.e., the dissociation activation energy) of two gaseous complexes composed of a $26.5-\mathrm{kDa}$ single-chain variable fragment $(\mathrm{scFv})$ of a monoclonal antibody and the $\alpha \mathrm{Gal}[\alpha \mathrm{Abe}] \alpha \mathrm{Man}$ trisaccharide were investigated using the blackbody infrared radiative dissociation (BIRD) technique, implemented with Fourier transform ion cyclotron resonance (FTICR)/MS. One of the gaseous complexes was produced by transferring the specific complex from aqueous solution to the gas phase with nanoES. The second complex was produced by nonspecific interactions during the nanoES process. This study revealed that at the charge states investigated $(+10$ and +11$)$, the nonspecific complex was kinetically more stable and, in the case of the +10 charge state, the nonspecific complex was energetically more stable than the specific complex. We proposed two possible explanations for the enhanced stability of the nonspecific complex, relative to the specific complex. First, we suggested that conformational constraints imposed by the specific interactions in solution may prevent the specific complex from adopting a lower energy structure in the gas phase, whereas the non specific complex, unencumbered by such constraints, is able to explore a greater region of conformational space and relaxes to a lower energy structure. As an alternative explanation, we suggested that strong ionic hydrogen bonding, which is believed to be absent in the gaseous-specific complex, might contribute to the stability of the nonspecific complex. The ionic hydrogen bond(s) in this case would likely involve the solvation of a protonated basic residue, such as arginine or histidine, by one or more carbohydrate hydroxyl groups. Support for the latter explanation was found in a comparison of Arrhenius parameters determined for the nonspecific $\mathrm{scFv} \cdot \alpha \mathrm{Gal}[\alpha \mathrm{Abe}] \alpha \mathrm{Man}$ complex and a second nonspecific complex, CA $\bullet \alpha \mathrm{Gal}$ $[\alpha$ Abe $] \alpha$ Man (CA, bovine carbonic anhydrase II) at the same charge states. The Arrhenius parameters for both complexes are indistinguishable, within experimental error, suggesting similar intermolecular interactions in both complexes. The absence of a dependence of carbohydrate binding on protein structure (primary or higher order) is consistent with the contribution of strong ionic hydrogen bonds to the stability of both complexes.

Recently, we used nanoES-FT-ICR/MS and BIRD to investigate the nonspecific interactions of CA and bovine ubiquitin (Ubq) with a series of carbohydrates, ranging in size from mono- to tetrasaccharides [16]. The goal of that study was to identify the factors that influence the tendency of proteins and carbohydrates to engage in long-lived nonspecific interactions during the nanoES process. Notably, it was found that the degree of nonspecific binding (i.e., the number of carbohydrates bound to a given protein) is insensitive to the charge state of the complex and, at high carbohydrate concentrations, the number of carbohydrates bound to the protein can significantly exceed the charge state. Based on these results, it was concluded that formation of the nonspecific complexes is not governed simply by charge solvation and that neutral interactions also can contribute. However, BIRD experiments, performed simultaneously on the protein-carbohydrate complexes with a distribution of bound carbohydrates, revealed that in addition to being sensitive to the structure of the protein and carbohydrate, the number and type of 
charged groups influences the kinetic stability of the complexes. Interestingly, no simple relationship between charge state and kinetic stability was evident.

The aforementioned studies provide indirect evidence that both neutral and ionic intermolecular interactions may play a role in stabilizing the nonspecific protein-carbohydrate complexes in the gas phase. However, the contribution of these interactions, and the influence of the charge state, the structure of the protein and carbohydrate, and the number of bound carbohydrates thereon, is unclear. Here, in an effort to more fully evaluate the nature of the intermolecular interactions responsible for the nonspecific complexes, we have performed the first comprehensive study of the dissociation kinetics and energetics of protein-ligand complexes arising from nonspecific interactions formed during nanoES. Using BIRD and FT-ICR/MS, timeresolved thermal dissociation experiments were performed on a series of 1:1 protein-carbohydrate complexes formed between the proteins $\mathrm{CA}, \mathrm{Ubq}$ and bovine pancreatic trypsin inhibitor (BPTI), and carbohydrates ranging in size from mono- to tetrasaccharides. From an analysis of the Arrhenius parameters determined for a series of protonated and deprotonated 1:1 protein-trisaccharide complexes, the influence of charge state, protein structure, and carbohydrate structure on the kinetic and energetic stability of the nonspecific complexes was assessed. BIRD also was performed on a number of 1:2 protein-trisaccharide complexes to establish whether the proteins present a unique and independent carbohydrate binding site in the gas phase.

\section{Experimental Procedures}

\section{Proteins and Carbohydrates}

Bovine CA (molecular weight [MW], 29,089 Da), bovine Ubq (MW, $8565 \mathrm{Da})$, and BPTI (MW, $6517 \mathrm{Da})$, were purchased from Sigma-Aldrich Co. (Oakville, Canada) and used without further purification. The monosaccharide D-Gal (1) was purchased from Sigma Canada and the carbohydrates $\alpha$ Abe $\left(2-\mathrm{O}-\mathrm{CH}_{3}-\alpha \mathrm{Man}\right)$ (2), $\alpha \operatorname{Tal}[\alpha$ Abe $] \alpha$ Man (3), $\alpha$ Abe (2-O-CH $-\alpha$ Man $) \alpha$ Glc $\beta$ Glc (4), $\alpha \operatorname{Gal}[\alpha \mathrm{Abe}] \alpha \mathrm{Man}$ (5), $\alpha \operatorname{Gal}[\alpha \mathrm{Abe}](4-$ deoxy- $\alpha$ Man) (6), and (6-deoxy- $\alpha \mathrm{Gal})[\alpha \mathrm{Abe}] \alpha \mathrm{Man}$ (7) were provided by D. R. Bundle (University of Alberta, Edmonton, Canada). The structures of the carbohydrates are shown in Figure 1.

\section{Mass Spectrometry}

Gaseous complexes were produced by nanoES performed on aqueous solutions of protein $(\sim 10 \mu \mathrm{M})$, carbohydrate (40-80 $\mu \mathrm{M})$, and ammonium acetate (1 $\mathrm{mM})$. The nanoES tips were constructed from aluminosilicate capillaries (1-mm outer diameter [o.d.], 0.68-mm inner diameter [i.d.]) pulled to an $\sim 4$ - to $7-\mu \mathrm{m}$ o.d. at one end using a P-2000 micropipette puller (Sutter Instruments, Novato, CA). The electric field required to spray the solution was established by applying a voltage of $\pm 800-1000 \mathrm{~V}$ to a platinum wire inserted inside the glass tip. The solution flow rate was typically 20-50 $\mathrm{nL} / \mathrm{min}$. The droplets and gaseous ions produced by nanoES were introduced into the vacuum chamber of a modified ApexII 47e FT-ICR mass spectrometer (Bruker, Billerica, MA) through a stainless steel capillary (i.d., $0.43 \mathrm{~mm}$ ) maintained at an external temperature of $66{ }^{\circ} \mathrm{C}$ [17]. The ions and charged droplets sampled by the capillary $( \pm 48-52 \mathrm{~V})$ were transmitted through a skimmer $( \pm 0-2 \mathrm{~V})$ and trapped, electrodynamically, in an rf hexapole. Ions were accumulated in the hexapole for $2 \mathrm{~s}$ and then ejected and accelerated $( \pm 2700 \mathrm{~V})$ into a 4.7-tesla superconducting magnet, decelerated, and introduced into the ion cell. The trapping plates of the cell were maintained at a constant potential $( \pm 1.4-1.8 \mathrm{~V})$ throughout the experiment. The typical base pressure for the instrument was $\sim 5 \times 10^{-10}$ mbar. The temperature of the ion cell was controlled with two external flexible heating blankets placed around the vacuum tube in the vicinity of the cell [18].

Data acquisition was controlled by an SGI R5000 computer running the Bruker Daltonics XMASS software, version 5.0. Mass spectra were obtained using standard experimental sequences with chirp broadband excitation. Isolation of the reactant ions for the BIRD experiments was achieved using a combination of single rf and broadband rf sweep excitation. The isolated ions were stored inside the heated cell for varying reaction times before excitation and detection. The time-domain signal, consisting of the sum of 30-60 transients containing $128 \mathrm{~K}$ data points per transient, was subjected to one zero-fill before Fourier transformation.

\section{Results and Discussion}

\section{Formation of 1:1 and 1:2 Nonspecific Protein-Carbohydrate Complexes}

As shown previously, nonspecific protein-carbohydrate complexes are readily produced by nanoES performed on solutions of protein and carbohydrate, with an initial concentration ratio of [carbohydrate]/[protein] $>2$ [17]. In this work, aqueous solutions containing $10 \mu \mathrm{M}$ of protein (CA, Ubq, or BPTI) and $40-80 \mu \mathrm{M}$ of carbohydrate (1-7) were used to generate protonated and deprotonated nonspecific 1:1 and 1:2 protein-carbohydrate complexes by nanoES. Shown in Figure 2 are illustrative nanoES mass spectra obtained from solutions of 3 with CA and $\mathrm{Ubq}$ in positive and negative ion mode and with BPTI in positive ion mode. At these concentrations, the major ions observed in positive ion mode correspond to the protonated unbound protein $(\mathrm{P}+n \mathrm{H})^{n+} \equiv \mathrm{P}^{n+}$, the $1: 1$ protein-carbohydrate complex $(\mathrm{P}+\mathrm{L}+n \mathrm{H})^{n+} \equiv(\mathrm{P}+\mathrm{L})^{n+}$, and the $1: 2$ protein-carbohydrate complex $(\mathrm{P}+2 \mathrm{~L}+n \mathrm{H})^{n+} \equiv$ $(\mathrm{P}+2 \mathrm{~L})^{n+}$ (Figure 2a, d, f). It should be noted that CA is a $\mathrm{Zn}(\mathrm{II})$-containing metalloenzyme and the zinc co- 


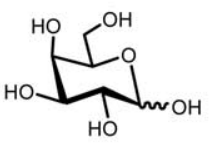

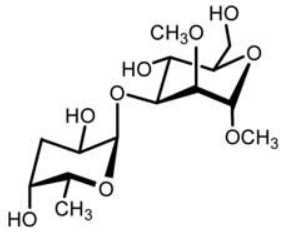

2

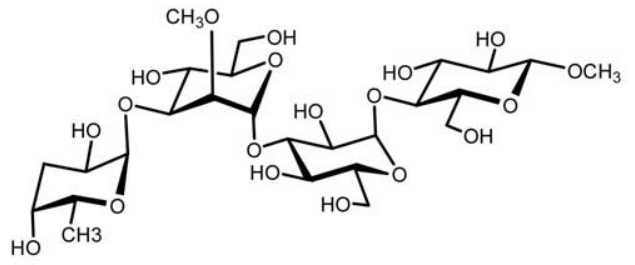

4

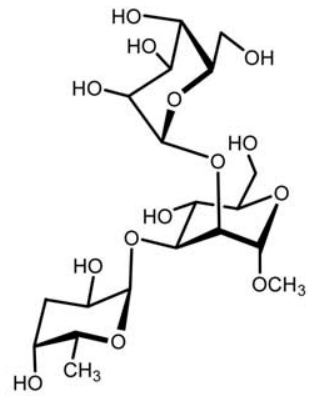

3

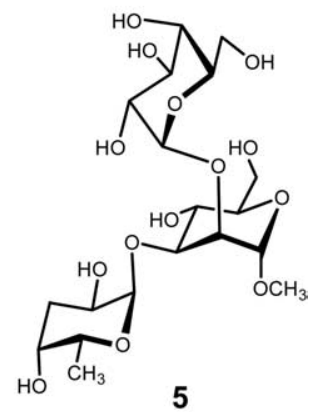

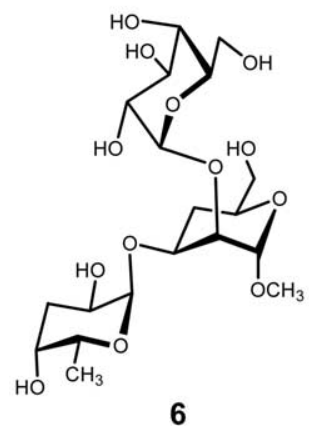

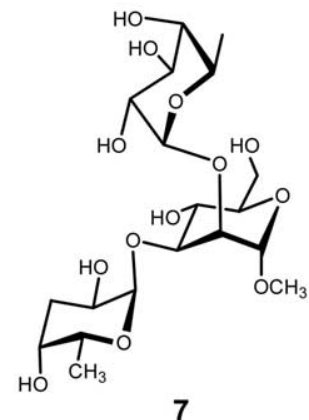

Figure 1. Structures of the carbohydrates: D-Gal (1), $\alpha$ Abe(2-O- $\left.\mathrm{CH}_{3}-\alpha \mathrm{Man}\right)(2), \alpha \mathrm{Tal}[\alpha \mathrm{Abe}] \alpha \mathrm{Man}(3)$, $\alpha$ Abe(2-O- $\left.\mathrm{CH}_{3}-\alpha \mathrm{Man}\right) \alpha \mathrm{Glc} \beta$ Glc (4), $\alpha \mathrm{Gal}[\alpha \mathrm{Abe}] \alpha \operatorname{Man}$ (5), $\alpha \mathrm{Gal}[\alpha \mathrm{Abe}](4-\mathrm{deoxy}-\alpha \mathrm{Man})$ (6), and (6deoxy- $\alpha \mathrm{Gal})[\alpha \mathrm{Abe}] \alpha \operatorname{Man}(7)$.

factor is expected to contribute to the charge state of the CA ions in the gas phase [19]. The CA ions are typically observed at charge states of +9 to +12 , and the Ubq and BPTI ions are observed at +5 and +6 . A modest shift in the charge state distribution of the protein and complex ions could be achieved through the addition of imidazole to the nanoES solution. Imidazole is a relatively strong base in the gas phase (gas-phase basicity $=217$ $\mathrm{kcal} / \mathrm{mol}[20]$ ) and can effect proton abstraction from the protonated protein and complex ions in the source region. For example, the addition of $0.1 \mathrm{mM}$ of imidazole to a solution of CA and carbohydrate shifts the charge state distribution of the protein and complex ions to +8 to +11 (Figure $2 b$ ). NanoES mass spectra also were measured for solutions of 3 with CA and with Ubq in negative ion mode. The major species observed are the deprotonated protein and 1:1 complex $\mathrm{P}^{z-}$ and $(\mathrm{P}+$
$\mathrm{L})^{z-}$, at charge states $z=9-11$ for CA (Figure 2c) and $z$ $=4-5$ for Ubq (Figure 2e).

\section{Dissociation Pathways}

BIRD experiments were performed on the protonated 1:1 complexes of CA with $\mathbf{1}, \mathbf{2}$, and 4-7 at charge states $n=10$ and 11 and with 3 at charge states $n=8-12$ and $z=9$, the 1:1 complexes of Ubq with 1-5 at $n=5$ and with 3 at $z=5$ and the 1:1 complex of BPTI with 5 at $n$ $=5$. BIRD was also performed on the protonated 1:2 complexes of CA at $n=10$ and 11 and Ubq at $n=5$ with two molecules of 3 . Over the range of temperatures investigated $\left(60-190{ }^{\circ} \mathrm{C}\right)$, BIRD of the $(\mathrm{P}+\mathrm{L})^{n+/ z-}$ ions proceeds exclusively by the dissociation of the noncovalent intermolecular interactions, with the carbohydrate lost as a neutral (eq 1). From double resonance 


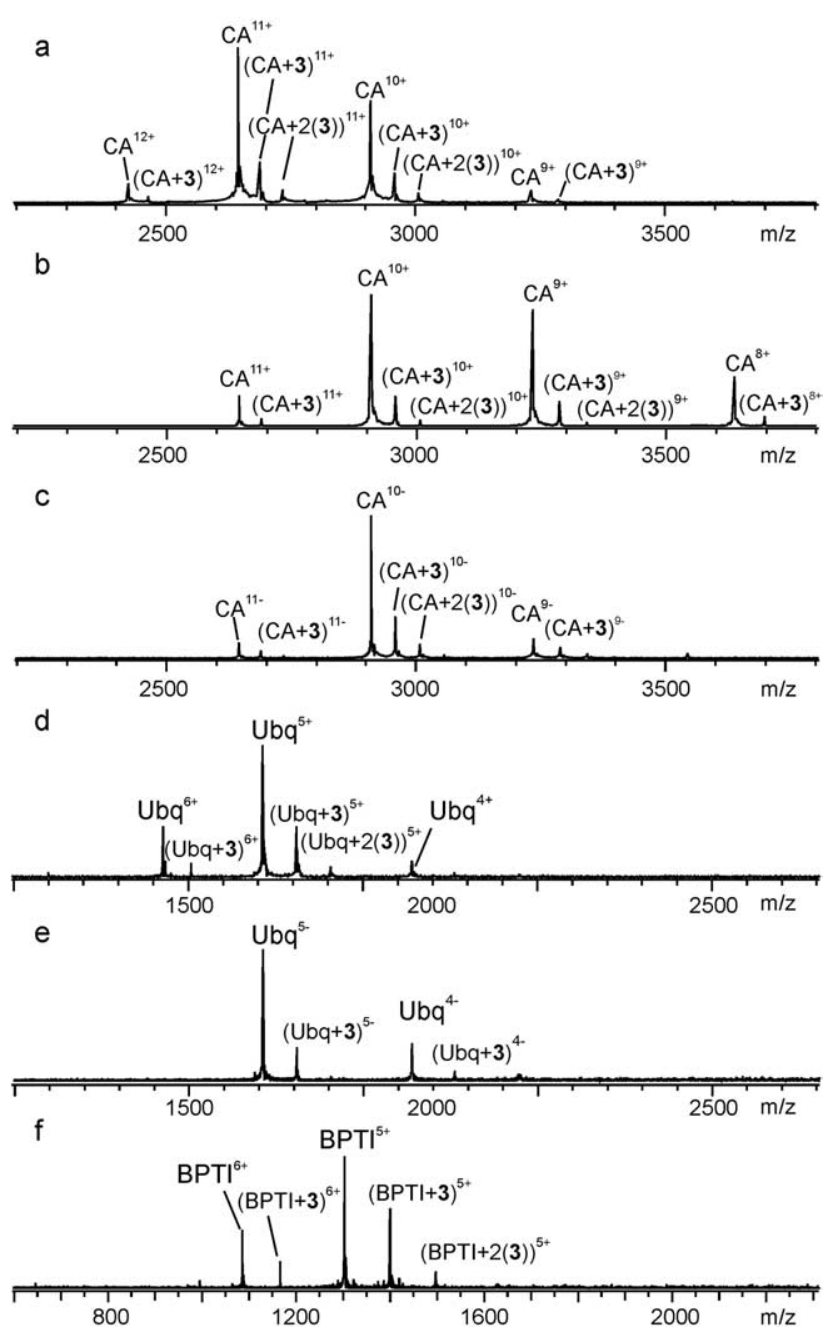

Figure 2. NanoES mass spectra obtained in positive ion mode from solutions of protein and 3, (a) $10 \mu \mathrm{M}$ of CA and $47 \mu \mathrm{M}$ of 3; (b) $10 \mu \mathrm{M}$ of CA and $47 \mu \mathrm{M}$ of 3 with $0.1 \mathrm{mM}$ of imidazole; (d) 10 $\mu \mathrm{M}$ of Ubq and $45 \mu \mathrm{M}$ of 3; (f) $10 \mu \mathrm{M}$ of BPTI and $63 \mu \mathrm{M}$ of 3 , and nanoES mass spectra obtained in the negative ion mode from solutions of protein and 3, (c) $10 \mu \mathrm{M}$ of CA and $53 \mu \mathrm{M}$ of 3 and (e) $10 \mu \mathrm{M}$ of Ubq and $41 \mu \mathrm{M}$ of 3 .

experiments, where suspected reaction intermediates are continuously ejected from the ion cell during BIRD, it was conclusively established that dissociation of the protonated 1:2 complexes $(\mathrm{P}+2 \mathrm{~L})^{n+}$ proceeds exclusively by the sequential loss of neutral carbohydrate molecules (eq 2).

$$
\begin{aligned}
& (\mathrm{P}+\mathrm{L})^{\mathrm{n}+/ z^{-}} \rightarrow \mathrm{P}^{\mathrm{n}+/ z^{-}}+\mathrm{L} \\
& (\mathrm{P}+2 \mathrm{~L})^{\mathrm{n}+} \rightarrow(\mathrm{P}+\mathrm{L})^{\mathrm{n}+}+\mathrm{L} \rightarrow \mathrm{P}^{\mathrm{n}+}+2 \mathrm{~L}
\end{aligned}
$$

\section{Dissociation Kinetics}

The kinetic data for the dissociation of the 1:1 and 1:2 complexes were analyzed by plotting the natural logarithm of the normalized abundance of the complex $A_{\mathrm{PL} q}$ versus reaction time $t$. $A_{\mathrm{PL} q}$ was calculated using eq 3:
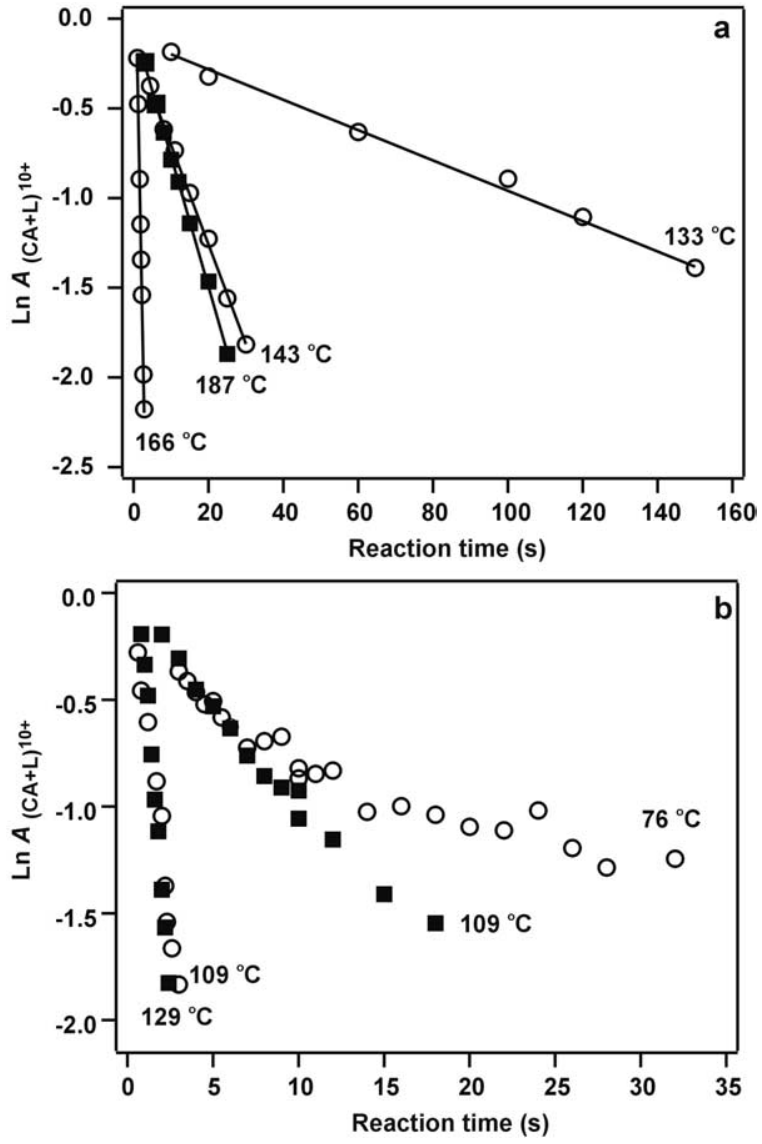

Figure 3. Plots of the natural logarithm of the normalized abundance of the complex ion $(C A+L)^{10+}$, where $L=1-4$, versus reaction time at the temperatures indicated: (a) open circle, $\mathrm{L}=3$; filled square, $\mathrm{L}=\mathbf{4}$; $(\mathrm{b})$ open circle, $\mathrm{L}=\mathbf{1}$; filled square, $\mathrm{L}=\mathbf{2}$.

$$
A_{\mathrm{PL}_{\mathrm{q}}}=I_{\mathrm{PL}_{\mathrm{q}}} / \sum_{\mathrm{q}=0,1,2} I_{\mathrm{PL}_{\mathrm{q}}}
$$

where $I_{\mathrm{PLq}}$ is the measured ion intensity of the protein bound to $q$ carbohydrate molecules. Over the range of temperatures investigated, dissociation of the 1:1 complexes containing a tri- or tetrasaccharide (3-7) proceeds by simple first-order kinetics, that is, plots of $\ln A_{\mathrm{PL} q}$ versus $t$ are linear and the slope is equal to the negative of the dissociation rate constant $k$ :

$$
\ln \left(A_{\mathrm{PL}_{\mathrm{q}}}\right)=-k t
$$

Furthermore, the kinetic data are highly reproducible and insensitive to the protein and carbohydrate concentrations or nanoES/source conditions used. Illustrative plots of the kinetic data measured for the $(\mathrm{CA}+\mathrm{L})^{10+}$ and $(\mathrm{Ubq}+\mathrm{L})^{5+}$ ions, where $\mathrm{L}=\mathbf{3}$ and $\mathbf{4}$, are shown in Figures $3 \mathrm{a}$ and $4 \mathrm{a}$. In contrast, the rate of dissociation of the complexes containing the mono- (1) or disaccharide (2) decreases with reaction time, the magnitude of the change in reaction rate being most significant at the lowest reaction temperatures studied. In addition, the kinetic data tend to be less reproducible than is the case for complexes of 3-7. Kinetic data measured for the (CA 

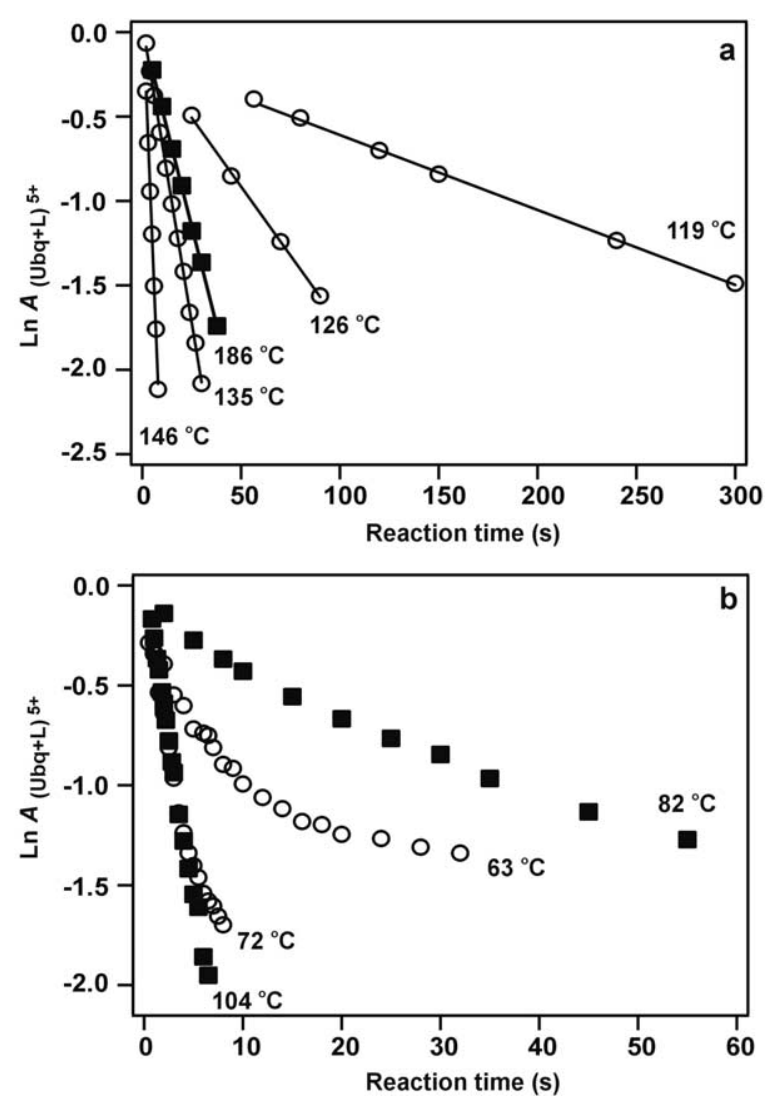

Figure 4. Plots of the natural logarithm of the normalized abundance of the complex ion $(\mathrm{Ubq}+\mathrm{L})^{5+}$, where $\mathrm{L}=\mathbf{1 - 4}$, versus reaction time at the temperatures indicated: (a) open circle, $\mathrm{L}=3$; filled square, $\mathrm{L}=4 ;(\mathrm{b})$ open circle, $\mathrm{L}=\mathbf{1}$; filled square, $\mathrm{L}=\mathbf{2}$.

$+\mathrm{L})^{10+}$ and $(\mathrm{Ubq}+\mathrm{L})^{5+}$ ions, where $\mathrm{L}=\mathbf{1}$ and $\mathbf{2}$, are shown in Figures $3 b$ and $4 b$.

There are a number of possible explanations for the nonlinear first-order kinetic plots obtained for the complexes of $\mathbf{1}$ and 2 . If a given $(\mathrm{P}+\mathrm{L})^{n+}$ complex consists of multiple, noninterconverting conformers, for example, $(\mathrm{P}+\mathrm{L})_{\mathrm{C} 1}^{n+},(\mathrm{P}+\mathrm{L})_{\mathrm{C} 2}^{n+}$, with distinct dissociation rate constants, that is, $k_{\mathrm{C} 1}, k_{\mathrm{C} 2}, \ldots$ (Scheme 1), the observed rate of dissociation will reflect the relative abundance and reactivity of all of the conformers:

$$
\begin{aligned}
A_{\mathrm{PL}} & =\mathrm{f}_{\mathrm{C} 1} \exp \left(-k_{\mathrm{C} 1} t\right)+\mathrm{f}_{\mathrm{C} 2} \exp \left(-k_{\mathrm{C} 2} t\right) \\
& +\cdots+\mathrm{f}_{\mathrm{C} i} \exp \left(-k_{C i} t\right)
\end{aligned}
$$

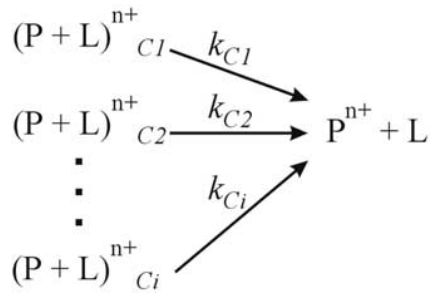

Scheme 1. Dissociation pathways for a protein-ligand complex $(\mathrm{P}+\mathrm{L})^{n+}$, which consists of multiple conformers with distinct dissociation rate constants.

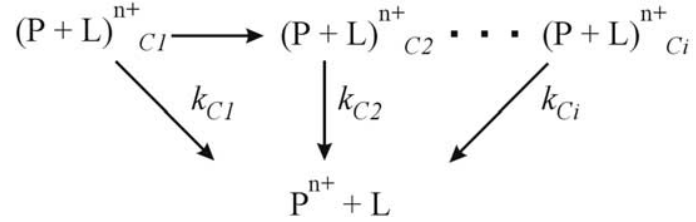

Scheme 2. Dissociation pathways for protein-ligand complex $(\mathrm{P}+\mathrm{L})^{n+}$, which undergoes conformation changes over the course of the reaction.

where $f_{\mathrm{C}}$ is the fractional abundance of a given conformer. Because of differences in the magnitude of the rate constants, the rate of dissociation will decrease with time because of the enhanced decay of the more reactive species. The contribution of kinetically distinct structures is a reasonable explanation given that the nonspecific binding process in ES, by its very nature, is expected to produce complexes with many different carbohydrate interaction sites (at least at the time of their formation). An alternative explanation that can not be discounted is the possible influence of thermally driven changes in the structure of the complex, which may occur over the course of reaction and, thereby, alter the rate of dissociation (Scheme 2). If such structural changes do indeed occur, the decrease in reaction rate with time indicates that the complexes become kinetically more stable with reaction time, presumably because of the formation of additional or stronger intermolecular interactions; that is, the complex relaxes to a lower energy state. Finally, changes in reaction rate in BIRD experiments can, in principle, arise from changes in the internal energy distribution of the reactant ions over the course of the reaction. Such a change in the energy distribution is expected when the ions are not in the rapid energy exchange (REX) limit; ions with internal energies greater than the dissociation threshold energy for dissociation will become depleted by dissociation resulting in a truncated Boltzmann distribution of internal energy [21, 22]. However, this explanation seems unlikely given the size of the ions and the fact that a change in reaction rate was not observed for all of the complexes. Furthermore, BIRD experiments performed on a number of small ions that were not in the REX limit yielded simple first-order kinetics [23], indicating that the internal energy distribution of the ions very rapidly reaches a steady state.

Perhaps more intriguing than the nonlinear kinetics plots obtained for complexes of $\mathbf{1}$ and $\mathbf{2}$ are the linear plots obtained for the 1:1 complexes of 3-7. The simple first-order kinetics are suggestive of gaseous $(\mathrm{P}+\mathrm{L})^{n+}$ ions with a single structure (in terms of the intermolecular interactions) or multiple kinetically equivalent structures. As discussed previously, the nonspecific association process in ES is expected to generate a number of structurally distinct complexes in which the carbohydrate is bound at different sites on the protein. One possible explanation for the observed dissociation kinetics is that the nonspecific complexes, independent 
of their original structure (i.e., carbohydrate binding site), rapidly relax to a single structure or multiple equivalent structures in the gas phase. In other words, the proteins have preferred carbohydrate binding sites in the gas phase, which the carbohydrate molecules are able to rapidly access (relative to the time scale of the experiment). In an effort to establish whether the nonspecific protein-trisaccharide complexes adopt a single preferred binding structure or whether multiple equivalent binding sites exist, BIRD was performed on the nonspecific 1:2 complexes of CA and Ubq with 3 and the results were compared with the kinetic data of the corresponding 1:1 complexes. Shown in Figure 5 are plots of $\ln \left(A_{\mathrm{PL} q}\right)$ versus $t$ obtained for the (CA + $2(3))^{10 / 11+}$ and $(\mathrm{Ubq}+2(3))^{5+}$ ions. It can be seen that the kinetic plots obtained for the three complex ions are linear over the range of temperatures investigated, allowing for the accurate determination of dissociation rate constant $k_{\text {obs }}$. Because dissociation of the complex is expected to proceed via parallel pathways involving the loss of either of the carbohydrates $\mathrm{L}_{1}$ and $\mathrm{L}_{2}$ (Scheme 3 ), $k_{\mathrm{obs}}$ will be equal to the sum of the individual dissociation rate constants (i.e., $k_{\mathrm{obs}}=k_{1}+k_{2}$ ). If the binding sites are equivalent (kinetically) and independent, $k_{\mathrm{obs}}$ will be equal to twice the rate constant $\left(k_{1: 1}\right)$ measured for the dissociation of the 1:1 complexes, that is, $k_{\mathrm{obs}}=$ $2\left(k_{1: 1}\right)$. If the binding sites are nonequivalent and independent, then $k_{\mathrm{obs}} \neq 2\left(k_{1: 1}\right)$. Plots of the ratio $k_{\mathrm{obs}} / k_{1: 1}$ versus reaction temperature for the three ions are shown in Figure 6. For the $(\mathrm{CA}+2(3))^{10+}$ and $(\mathrm{Ubq}+$ $2(3))^{5+}$ ions, $k_{\mathrm{obs}} / k_{1: 1} \geq 2$, and for $(\mathrm{CA}+2(3))^{11+}$, $k_{\mathrm{obs}} / k_{1: 1}<2$; and for all three ions the ratio decreases with increasing temperature. Taken on their own, these results suggest that the carbohydrate binding sites are not equivalent. However, this interpretation assumes that the binding sites are independent of one another. To establish the independence of carbohydrate binding sites, the change in relative abundance of the 1:2 complex $\left(\left(\mathrm{P}+\mathrm{L}_{1}+\mathrm{L}_{2}\right)^{n+}\right)$, the 1:1 complex (the sum of the intermediates $\left(\mathrm{P}+\mathrm{L}_{1}\right)^{n+}$ and $\left.\left(\mathrm{P}+\mathrm{L}_{2}\right)^{n+}\right)$ and the 1:0 species (the unbound protein $\mathrm{P}^{n+)}$ with $t$ was compared with values calculated according to different kinetic models. Three different kinetic models, all based on the reaction pathways described in Scheme 3, were considered. In model I the nonspecific binding sites are nonequivalent and independent, such that $k_{1}=k_{1}^{\prime}=k_{1: 1}$ and $k_{2}=k_{2}^{\prime}=k_{\mathrm{obs}}-k_{1: 1}$. In the other two models, the binding sites are treated as equivalent but dependent. In model II, $k_{1}=k_{2}=k_{\text {obs }} / 2$ and $k_{1}^{\prime}=k_{2}^{\prime}=k_{1: 1}$ and in model III, $k_{1}=k_{2}=k_{1}^{\prime}=k_{2}^{\prime}=k_{\mathrm{obs}} / 2$. To determine whether any one of these models describes the dissociation kinetics measured experimentally, the breakdown curves simulated from these kinetic models were compared with the kinetic data measured for the 1:2 complexes, $(\mathrm{CA}+2(3))^{10+},(\mathrm{CA}+2(3))^{11+}$, and $(\mathrm{Ubq}+$ $2(3))^{5+}$. Because the ratio $k_{\mathrm{obs}} / k_{1: 1}$ measured for the complexes $(\mathrm{CA}+2(3))^{10+}$ and $(\mathrm{Ubq}+2(3))^{5+}$ at high reaction temperatures and for $(\mathrm{CA}+2(3))^{11+}$ at low reaction temperatures are close to 2 , the values of
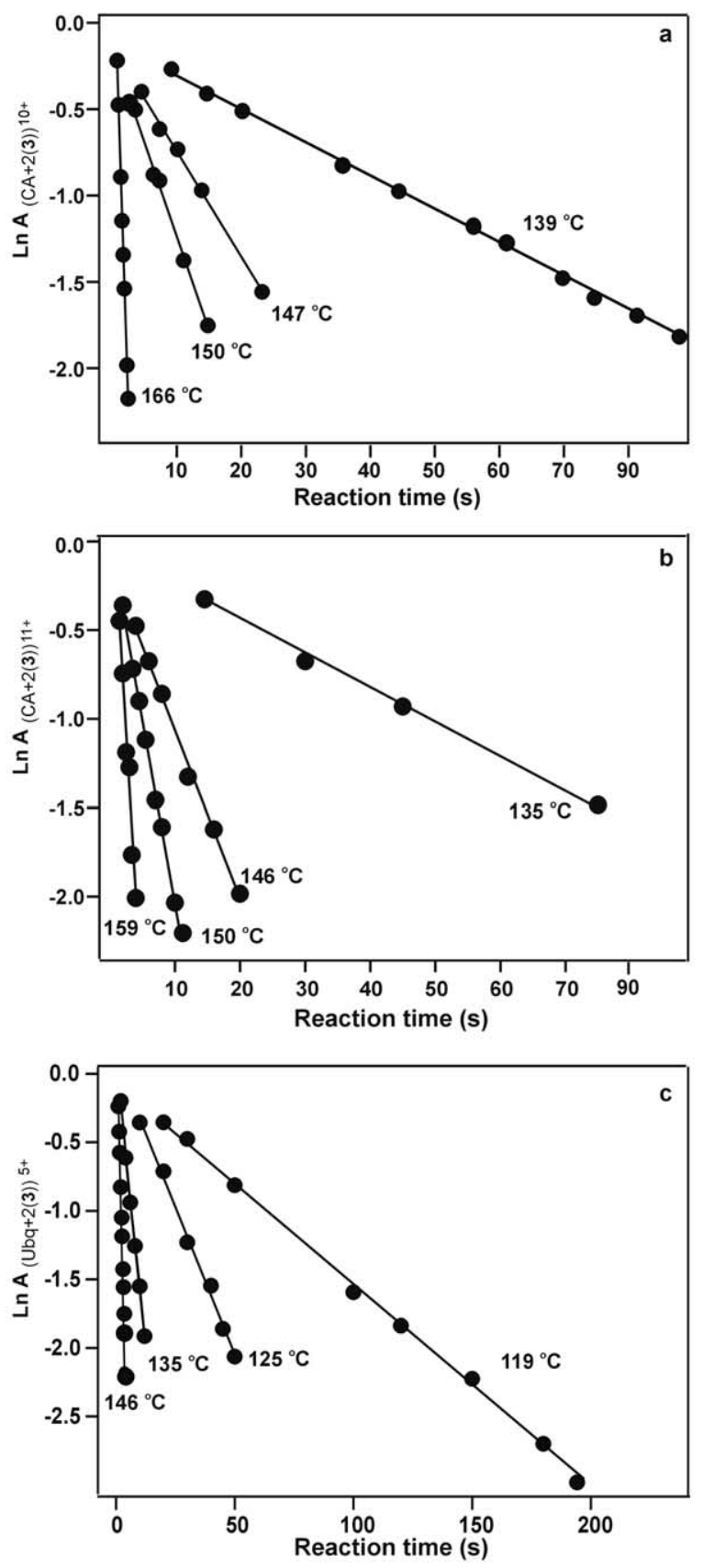

Figure 5. Plots of the natural logarithm of the normalized abundance of the complex ion (a) $(\mathrm{CA}+2(3))^{10+},(\mathbf{b})(\mathrm{CA}+$ $2(3))^{11+}$, and $(\mathrm{c})(\mathrm{Ubq}+2(3))^{5+}$, versus reaction time at the temperatures indicated.

$k_{\mathrm{obs}} / 2, k_{\mathrm{obs}}-k_{1: 1}$, and $k_{1: 1}$ are similar, making it difficult to distinguish between the theoretical curves derived from the different kinetic models. Therefore, the comparison of the theoretical and experimental breakdown curves was performed on the kinetic data obtained at a relatively low reaction temperature for the $(\mathrm{CA}+$ $2(3))^{10+}$ and $(\mathrm{Ubq}+2(3))^{5+}$ ions, 139 and $119{ }^{\circ} \mathrm{C}$, respectively, and relatively high temperature for (CA + $2(3))^{11+}, 150{ }^{\circ} \mathrm{C}$. Shown in Figure 7 are the theoretical and experimental breakdown curves for the three ions. 


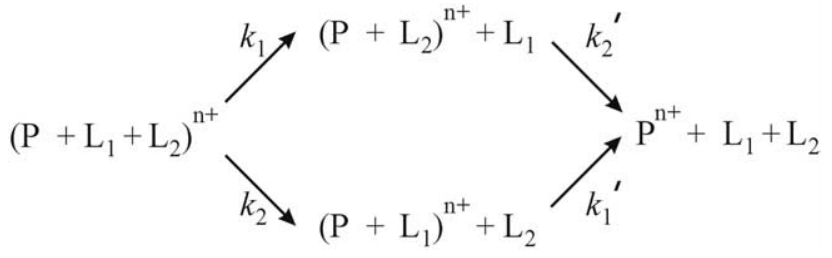

Scheme 3. Sequential dissociation pathways for a 1:2 complex (P $\left.+\mathrm{L}_{1}+\mathrm{L}_{2}\right)^{n+}$. $\mathrm{L}_{1}$ and $\mathrm{L}_{2}$ correspond to the same carbohydrate bound at two different sites.

It can be seen that the kinetic data measured for the (CA $+2(3))^{10+}$ and $(\mathrm{CA}+2(3))^{11+}$ ions are best described by a model in which the two binding sites are equivalent but dependent. In the case of $(\mathrm{CA}+2(3))^{10+}$, neither binding site resembles (kinetically) the interaction in the 1:1 complex, which means that the addition of the second carbohydrate changes irreversibly (at least on the time scale of the experiment) the protein-carbohydrate interactions (i.e., $k_{1}=k_{2}=k_{1}^{\prime}=k_{2}^{\prime}=k_{\text {obs }} / 2$, Model III). For $(\mathrm{CA}+2(3))^{10+}$, after the loss of one of the carbohydrates, the remaining carbohydrate resembles (kinetically) the 1:1 complex (i.e., $k_{1}=k_{2}=k_{\text {obs }} / 2$ and $k_{1}^{\prime}$ $=k_{2}^{\prime}=k_{1: 1}$, Model II). In contrast to the results obtained for the $(\mathrm{CA}+2(3))^{10 / 11+}$ ions, which indicate the presence of equivalent but dependent binding sites in the gas phase, the kinetic data measured for $(\mathrm{Ubq}+$ 2(3) $)^{5+}$ are best reproduced by Model I in which the binding sites are nonequivalent and independent (i.e., $k_{1}=k_{1}^{\prime}=k_{1: 1}$ and $\left.k_{2}=k_{2}^{\prime}=k_{\mathrm{obs}}-k_{1: 1}\right)$. This intriguing result suggests that there is a single, preferred carbohydrate interaction site on $\mathrm{Ubq}$ in the gas phase. If one accepts that at the time of their formation, the carbohydrates in the 1:1 and 1:2 complexes sample a variety of sites on Ubq, then this result implies that the carbohydrates are able to migrate rapidly to the preferred binding sites in the gas phase or, perhaps, in the

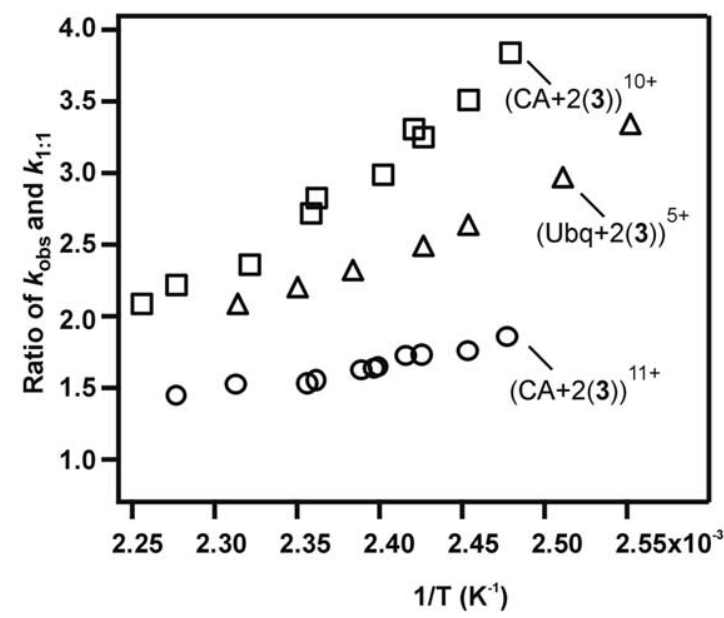

Figure 6. Plots of $k_{\mathrm{obs}} / k_{1: 1}$, the ratio of the rate constant of the dissociation of 1:2 complex ion and the rate constant for the dissociation of corresponding 1:1 complex ion, versus reaction temperature (open square, $(\mathrm{CA}+(2) 3)^{10+}$; open circle, $(\mathrm{CA}+$ $(2) 3)^{11+}$, and open triangle, $\left.(\mathrm{Ubq}+(2) 3)^{5+}\right)$.
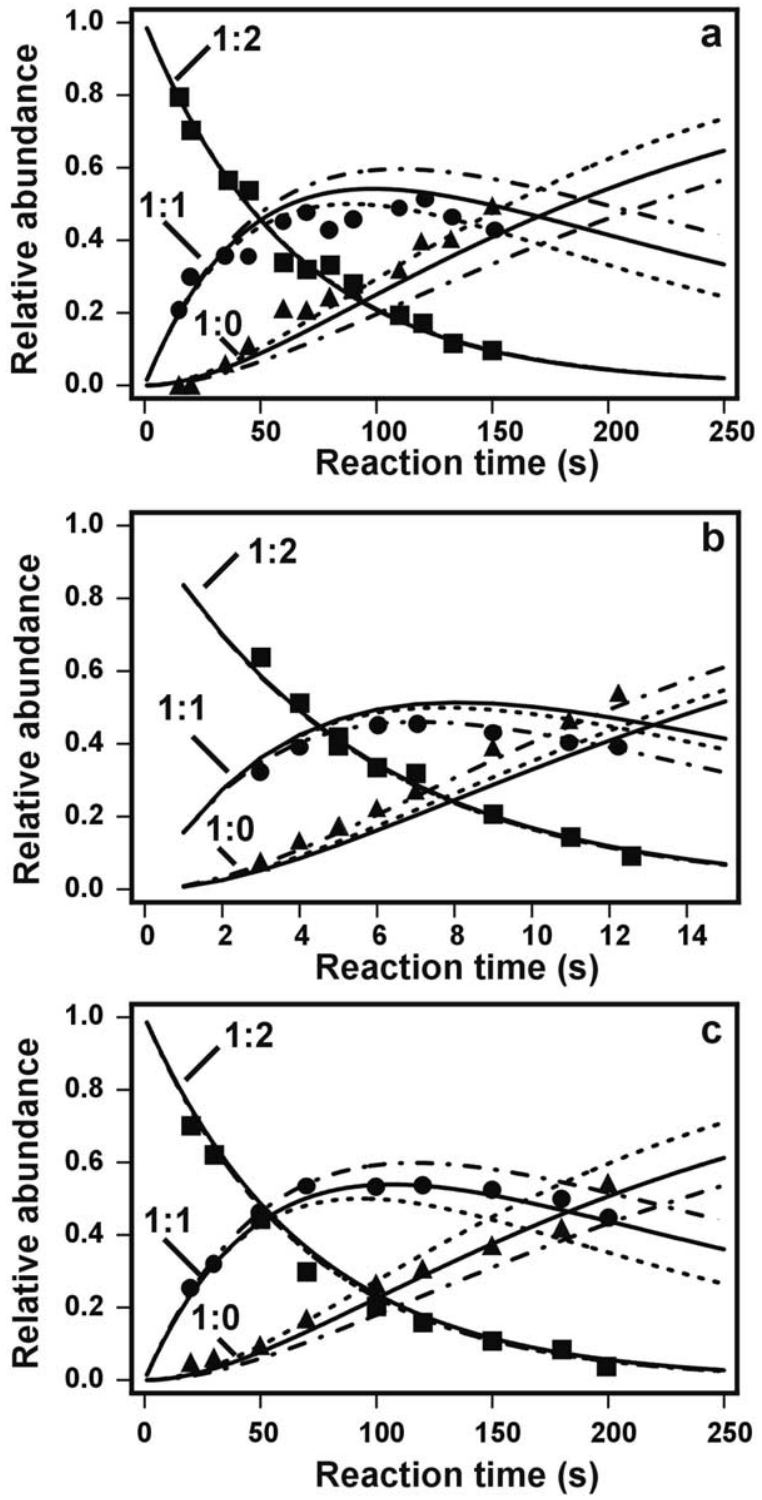

Figure 7. Comparisons of the experimental breakdown curves derived from the kinetic data for the complexes: $(a)(C A+2(3))^{10+}$ at $139^{\circ} \mathrm{C} ;(\mathbf{b})(\mathrm{CA}+2(3))^{11+}$ at $150^{\circ} \mathrm{C} ;(\mathrm{c})(\mathrm{Ubq}+2(3))^{5+}$ at $119^{\circ} \mathrm{C}$, and the corresponding theoretical breakdown curves calculated using the Kinetic Model I $\left[k_{1}=k_{1}^{\prime}=k_{1: 1}\right.$ and $k_{2}=k_{2}^{\prime}=k_{\mathrm{obs}}-k_{1: 1}$ (solid line)], Kinetic Model II $\left[k_{1}=k_{2}=1 / 2 k_{\text {obs }}\right.$ and $k_{1}^{\prime}=k_{2}^{\prime}=k_{1: 1}$ (dashes)], and Kinetic Model III $\left[k_{1}=k_{2}=k_{1}^{\prime}=k_{2}^{\prime}=1 / 2 k_{\text {obs }}\right.$ (dots and dashes)]

droplets during the final stages of desolvation. This result may be relevant to ongoing efforts to establish the extent to which the intermolecular interactions present in specific protein-ligand complexes in solution are preserved on transfer of complexes to the gas phase by ES (or nanoES).

\section{Arrhenius Activation Parameters}

Arrhenius plots were constructed from the temperature-dependent dissociation rate constants measured for the loss of neutral ligand from the 1:1 nonspecific 

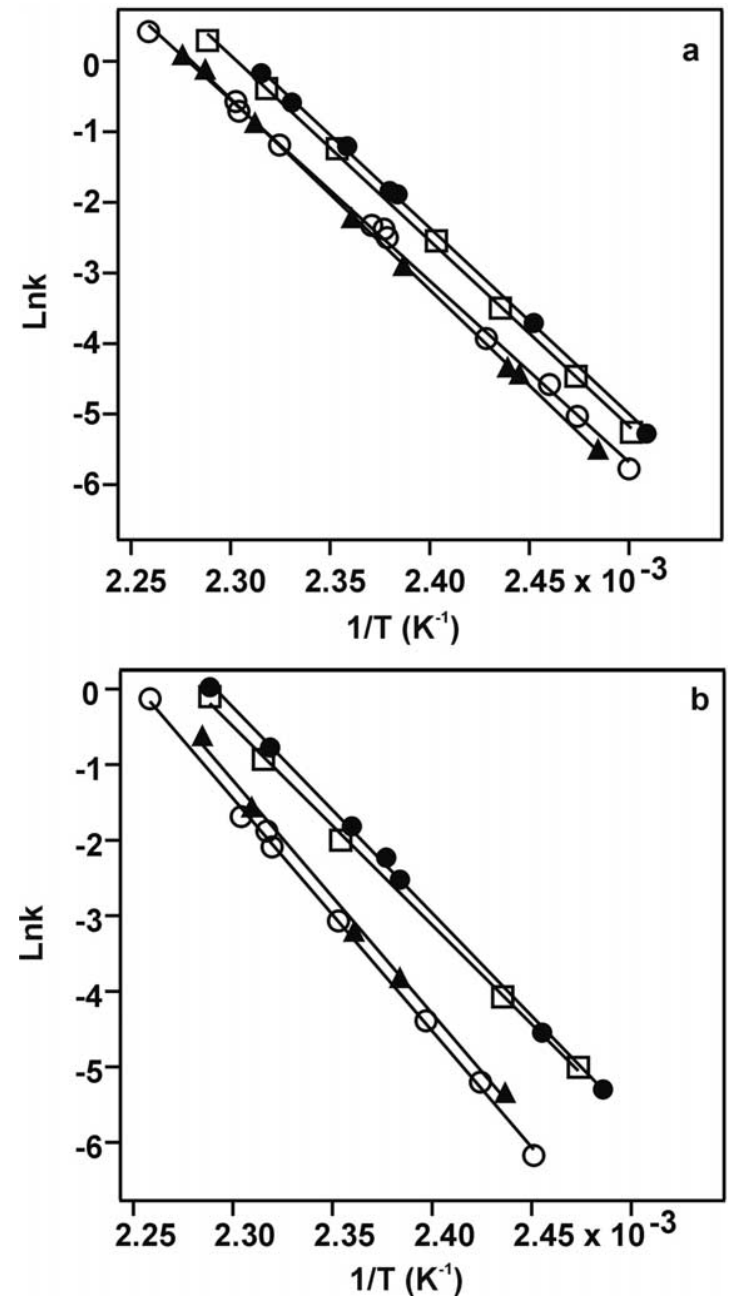

Figure 8. Arrhenius plots for the loss of $\mathrm{L}$ from the protonated complex ions $(\mathrm{CA}+\mathrm{L})^{n+}$, where $n$ is (a) 10 and (b) 11, (open circle, $\mathrm{L}=5$; filled triangle, $\mathrm{L}=3$; filled circle, $\mathrm{L}=6$; open square, $\mathrm{L}=$ 7).

complexes composed of $\mathrm{CA}, \mathrm{Ubq}$, or BPTI and one of the carbohydrates, 3 or 5-7 (Figures 8-10). The Arrhenius activation energy $E_{a}$ was determined from the slope of a linear least-squares fit of the Arrhenius plot and the preexponential $(A)$ factor was determined from the $y$ intercept. The Arrhenius activation parameters and the corresponding entropy of activation $\left(\Delta S^{\ddagger}\right)$, calculated at $415 \mathrm{~K}$ using eq 6 , are listed in Table 1 . Arrhenius plots could not be constructed for the complexes of CA and Ubq with 1 and 2 because of the difficulty in extracting reliable dissociation rate constants and with 4 because of the limited range of reaction temperatures that could be investigated with the present apparatus.

$$
A=\left(\mathrm{ek}_{\mathrm{B}} \mathrm{T} / \mathrm{h}\right) \exp \left(\Delta S^{\ddagger} / \mathrm{R}\right)
$$

Analysis of the Arrhenius parameters reveals that the kinetic and energetic stability of the nonspecific complexes is sensitive to a number of factors: the

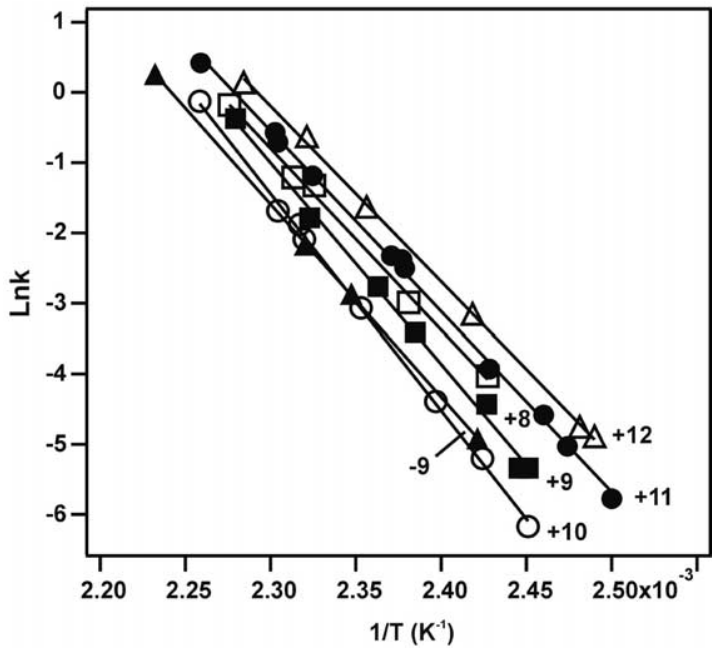

Figure 9. Arrhenius plots for the loss of 3 from the protonated complex ions $(\mathrm{CA}+3)^{n+/ z-}$ (open square, $n=8$; filled square, $n$ =9; open circle, $n=10$; filled circle, $n=11$; open triangle, (12); filled triangle, $z=9$ )

structure of the carbohydrate and protein and the charge state of the complex. Each of these factors and their influence on the stability of the complexes are discussed in the following paragraphs.

Influence of carbohydrate structure. Previous studies of the thermal dissociation of gaseous protein-carbohydrate complexes originating from specific interactions in solution have shown that the energetic and kinetic stability of the complexes are strongly influenced by intermolecular hydrogen bonds ( $\mathrm{H}$ bonds) between the protein and carbohydrate hydroxyl groups [10,11]. The nonspecific complexes are expected to be similarly stabilized and their stability should reflect the number of available H-bond donor/acceptor groups, in particular the number of hydroxyl groups. As described previously $[10,11]$, the contribution of individual car-

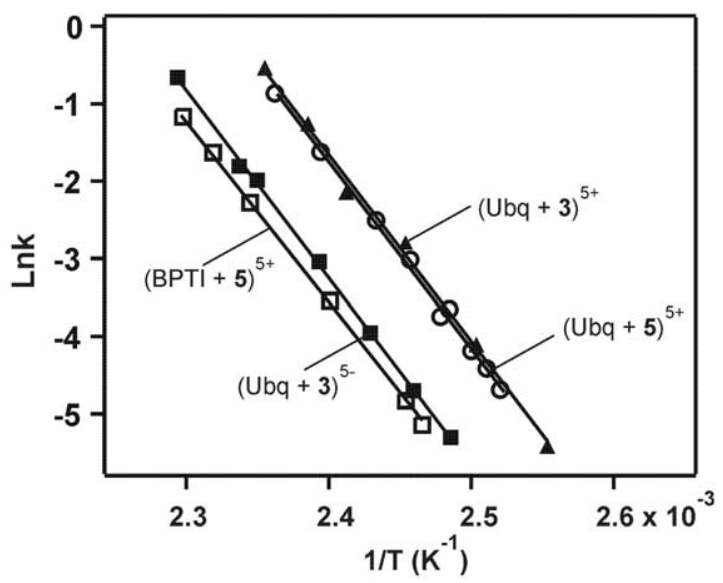

Figure 10. Arrhenius plots for the loss of $\mathrm{L}$ from the protonated and deprotonated complex ions (open circle, $(\mathrm{Ubq}+5)^{5+}$; filled triangle, $(\mathrm{Ubq}+3)^{5+}$; filled square, $(\mathrm{Ubq}+3)^{5-}$; and open square, $\left.(\mathrm{BPTI}+5)^{5+}\right)$. 
Table 1. Arrhenius parameters determined for the dissociation of gaseous, protonated, and deprotonated protein-trisaccharide $\frac{\text { complexes: }(\mathrm{P}+\mathrm{L})^{n+/ z-} \rightarrow \mathrm{P}^{n+/ z-}+\mathrm{L} \text {, where } \mathrm{L}=3 \text { and 5-7 }}{\text { Charge } E_{a}^{\mathrm{a}} \quad A^{\mathrm{a}} \quad \Delta S \ddagger^{\mathrm{b}}}$

\begin{tabular}{lrrrcc}
$\mathrm{P}$ & $\mathrm{L}$ & state & $(\mathrm{kcal} / \mathrm{mol})$ & $\left(\mathrm{s}^{-1}\right)$ & $(\mathrm{cal} / \mathrm{mol} \cdot \mathrm{K})$ \\
\hline \hline $\mathrm{CA}$ & $\mathbf{3}$ & +8 & $51.3 \pm 1.8$ & $10^{25.5} \pm 0.9$ & 56 \\
& $\mathbf{3}$ & +9 & $56.9 \pm 2.1$ & $10^{28.2} \pm 0.9$ & 68 \\
& $\mathbf{3}$ & +10 & $61.2 \pm 0.9$ & $10^{30.2} \pm 0.5$ & 77 \\
& $\mathbf{3}$ & +11 & $51.0 \pm 0.6$ & $10^{25.4} \pm 0.3$ & 55 \\
& $\mathbf{3}$ & +12 & $49.5 \pm 0.7$ & $10^{24.8} \pm 0.4$ & 52 \\
& $\mathbf{3}$ & -9 & $54.4 \pm 0.3$ & $10^{26.7} \pm 0.2$ & 61 \\
& $\mathbf{5}$ & +10 & $59.7 \pm 1.1^{\mathrm{c}}$ & $10^{29.5} \pm 0.5 \mathrm{c}$ & $74^{\mathrm{c}}$ \\
& $\mathbf{5}$ & +11 & $54.0 \pm 0.5^{\mathrm{c}}$ & $10^{27.0} \pm 0.3 \mathrm{c}$ & $62^{\mathrm{c}}$ \\
& $\mathbf{6}$ & +10 & $54.1 \pm 0.8$ & $10^{27.1} \pm 0.4$ & 63 \\
& $\mathbf{6}$ & +11 & $52.4 \pm 0.6$ & $10^{26.5} \pm 0.3$ & 60 \\
& $\mathbf{7}$ & +10 & $52.2 \pm 0.9$ & $10^{26.1} \pm 0.5$ & 58 \\
& $\mathbf{7}$ & +11 & $52.2 \pm 0.7$ & $10^{26.3} \pm 0.4$ & 59 \\
Ubq & $\mathbf{3}$ & +5 & $47.8 \pm 1.6$ & $10^{24.4} \pm 0.9$ & 51 \\
& $\mathbf{3}$ & -5 & $48.0 \pm 0.7$ & $10^{23.8} \pm 0.4$ & 48 \\
& $\mathbf{5}$ & +5 & $46.8 \pm 1.2$ & $10^{24.2} \pm 0.6$ & 50 \\
BPTI & $\mathbf{5}$ & +5 & $46.0 \pm 0.7$ & $10^{22.6} \pm 0.4$ & 42 \\
\hline
\end{tabular}

aThe reported errors are $1 \mathrm{SD}$.

${ }^{b}$ Values calculated at $415 \mathrm{~K}$ from the corresponding $A$ factors.

${ }^{\mathrm{C}}$ Arrhenius parameters taken from Ref. 15.

bohydrate $\mathrm{OH}$ groups to the stability of protein-carbohydrate complexes can be evaluated from the change in dissociation $E_{a}$ on deoxygenation of the carbohydrate at specific sites. The contribution of the Man C-4 and Gal C-6 OH groups to the energetic stability of the (CA + $5)^{n+}$ ions, where $n=10$ and 11, was assessed from the differences in the values of $E_{a}$ determined for the complex $(\mathrm{CA}+5)^{n+}$ and the corresponding complexes of the two monodeoxy congeners of $5,(\mathrm{CA}+6)^{n+}$, and $(\mathrm{CA}+7)^{n+}$. Deoxygenation at either site results in a decrease in $E_{a}$ of $6(6)$ and $8 \mathrm{kcal} / \mathrm{mol}(7)$ at +10 and 2 $\mathrm{kcal} / \mathrm{mol}(6$ and 7$)$ at +11 . The decrease in $E_{a}$ upon deoxygenation strongly suggests that both hydroxyl groups interact with CA in the gas-phase. Because of conformational constraints, the Gal C-6 and Man C-4 $\mathrm{OH}$ groups of $\mathbf{5}$ are not able to simultaneously solvate a single charge group such as a protonated amino group or protonated imidazole group. Assuming that the charge sites in the gaseous complex are not in close proximity to one another, these results indicate that one or both of the $\mathrm{OH}$ groups must be involved in neutral intermolecular $\mathrm{H}$ bonds. Although this result does not preclude the contribution of strong ionic $\mathrm{H}$ bonds (i.e., charge solvation) to the stability of the $(\mathrm{CA}+5)^{n+}$ ions, it does indicate that neutral interactions can play a significant role in stabilizing nonspecific protein-trisaccharide complexes. To investigate whether the configuration of individual carbohydrate $\mathrm{OH}$ groups (axial or equitoral) can influence the energetic stability of the complexes, the $E_{a}$ values measured for the (CA + $5)^{10 / 11+}$ and $(\mathrm{CA}+3)^{10 / 11+}$ ions were compared. The structures of 5 and 3 differ only in the configuration of the $\mathrm{OH}$ group at $\mathrm{C}-2$ of the nonreducing monosaccharide residue. At the +10 charge state, the $E_{a}$ values are indistinguishable, within experimental uncertainty, suggesting that either the $\mathrm{C}-2 \mathrm{OH}$ groups of $\mathbf{3}$ and $\mathbf{5}$ do not interact with the protein or that they engage in equivalent interactions. In contrast, at +11 , there is a difference of $3 \mathrm{kcal} / \mathrm{mol}$ in the $E_{a}$ values, a result that suggests a different energetic contribution from the C-2 $\mathrm{OH}$ group in these two complexes.

Influence of protein structure. The foregoing analysis reveals that the energetic stability of the nonspecific

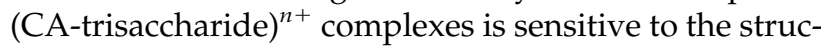
ture of the carbohydrate. There is also evidence that the complexes are stabilized by multiple interactions, some of which are neutral $\mathrm{H}$ bonds. Consequently, the structure of the protein and, in particular, the structure of protein surface presented to the carbohydrate might also be expected to influence the energetic stability of the nonspecific complexes. However, in a previous study [15], it was shown that the $E_{a}$ values for the dissociation of the protonated nonspecific 1:1 complexes of 5 with $\mathrm{CA}$ and with $\mathrm{scFv}$, at the same charge state $(+10$ and +11$)$, are indistinguishable, $\sim 60 \mathrm{kcal} /$ mol. This result suggests that protein structure (primary or higher order) does not significantly influence the energetic stability of the complex. This conclusion is further supported by the similar dissociation $E_{a}$ values $(\sim 47 \mathrm{kcal} / \mathrm{mol})$ determined in the present work for the $(\mathrm{BPTI}+5)^{5+}$ and $(\mathrm{Ubq}+5)^{5+}$ ions (Table 1$)$. An absence of a dependence of stability on protein structure for complexes at the same charge state could be interpreted to mean that the stabilizing intermolecular interactions are entirely ionic in nature. However, as described previously, there is compelling evidence, in the case of the $(\mathrm{CA}+5)^{10 / 11+}$ ions at least, that neutral interactions contribute to the stability of the proteintrisaccharide complexes. Assuming that neutral intermolecular interactions are generally present in the nonspecific protein-carbohydrate complexes, the present results imply that the bound carbohydrates are able to form energetically equivalent noncovalent interactions with the protein, independent of the nature of the functional groups on the surface of the protein. This surprising result may point to a significant role played by the protein backbone in stabilizing the nonspecific complexes.

Although the protein structure does not influence the value of $E_{a}$ for nonspecific complexes of the same charge state, it can influence kinetic stability. For example, the kinetic stability of the (BPTI +5$)^{5+}$ and $(\mathrm{Ubq}+$ $5)^{5+}$ ions are markedly different (at a given temperature), despite the similar $E_{a}$ values. The difference in kinetic stability reflects a significant difference in $\Delta S^{\ddagger}$, with the more stable (BPTI +5$)^{5+}$ having a $\Delta S^{\ddagger}$ that is $8 \mathrm{cal} / \mathrm{mol} \cdot \mathrm{K}$ smaller than that of $(\mathrm{Ubq}+5)^{5+}$. Differences in $\Delta S^{\ddagger}$ of similar magnitude also have been reported for the $(\mathrm{CA}+5)^{10 / 11+}$ versus $(\mathrm{scFv}+5)^{10 / 11+}$ ions [15]. The origin of these differences in $\Delta S^{\ddagger}$ is not currently known and is the focus of ongoing research in our laboratory. 
Influence of charge state. To evaluate the influence of the charge on the kinetic and energetic stability of the nonspecific complexes, the Arrhenius parameters determined for the $(\mathrm{CA}+3)^{n+}$ ions at charge states ranging from +8 to +12 were compared. It can be seen from Figure 10 and Table 1 that the kinetic and energetic stability of the complex over the range of temperatures investigated is sensitive to its charge state, with the stability being highest for the +10 charge state and decreasing for higher and lower charge states. The significant decrease in $E_{a}$ observed at charge states $\geq$ +10 is inconsistent with purely ionic intermolecular interactions stabilizing the complex. If binding was caused by solely ionic interactions, $E_{a}$ would be expected to increase with charge state because of the increasing acidity of protonated groups. The present results, therefore, likely reflect differences in the relative contribution of ionic and neutral interactions to the stability of the complex at the different charge states. Ion mobility measurements performed on a number of gaseous proteins produced by ES have shown that the protein ions adopt compact structures at low charge states and more extended or unfolded structures at higher charge states [24-29]. It is reasonable, therefore, to assume that of the charge states investigated, CA is in its most compact structure at +8 and that it adopts a more extended structure at higher charge states. Because proteins in more compact structures are able to more efficiently solvate charge [29], ionic interactions between the CA and 3 are expected to be weakest at +8 and increase with increasing charge. In contrast, the contribution of neutral interactions between CA and $\mathbf{3}$ is expected to diminish as the protein unfolds at higher charge states. Because of the opposite trends for the strength of the ionic and neutral intermolecular interactions with charge state, the stability of the nonspecific complex is expected to initially increase with charge and then decrease at higher charge states, in agreement with the observed trend in the $E_{a}$ values.

Additional support for the dominant influence of neutral intermolecular interactions at low charge states can be found in the similar $E_{a}$ values $(48 \mathrm{kcal} / \mathrm{mol})$ measured for the $(\mathrm{Ubq}+3)^{5+}$ and $(\mathrm{Ubq}+3)^{5-}$ ions (Table 1). Because of differences in the nature and location of the charge groups in the protonated and deprotonated ions, the energetic stabilities of the $(\mathrm{Ubq}+3)^{5+}$ and $(\mathrm{Ubq}+3)^{5-}$ ions would be expected to differ if ionic interactions are present. According to thermochemical data reported for the sequential hydration of $n-\mathrm{C}_{3} \mathrm{H}_{7} \mathrm{NH}_{3}^{+}$and $\mathrm{CH}_{3} \mathrm{COO}^{-}$ions $\left(n-\mathrm{C}_{3} \mathrm{H}_{7} \mathrm{NH}_{3}^{+}, \Delta \mathrm{H}_{0,1}^{\circ}=\right.$ $15.1 \mathrm{kcal} / \mathrm{mol}$ and $\Delta \mathrm{H}_{1,2}^{\circ}=11.6 ; \mathrm{CH}_{3} \mathrm{COO}^{-}, \Delta \mathrm{H}_{0,1}^{\circ}=$ 17.1 and $\left.\Delta \mathrm{H}_{1,2}^{\circ}=12.8[30,31]\right)$, which are the best available model systems for ionic $\mathrm{H}$ bonding between carbohydrates and protonated and deprotonated amino acids, stronger intermolecular interactions are expected in the case of the deprotonated complex (assuming the same degree of intramolecular charge solvation in the two cases). The similarity in the $E_{a}$ values determined for the $(\mathrm{Ubq}+3)^{5+/ 5-}$ ions, therefore, suggests that the complexes are stabilized predominantly by neutral intermolecular interactions. This conclusion is also consistent with the kinetic data obtained for the (Ubq + $2(5))^{5+}$ ion, which indicate the presence of a single preferred carbohydrate binding site. In contrast, the $(\mathrm{CA}+3)^{9+/ 9-}$ ions exhibit different $E_{a}$ values $(57$ $\mathrm{kcal} / \mathrm{mol}$ for +9 and $54 \mathrm{kcal} / \mathrm{mol}$ for -9 ), which is consistent with the contribution of both stabilizing ionic and neutral interactions. However, interpretation of the CA data is complicated by the presence of the zinc cofactor, which is expected to contribute to the charge state of the gaseous ions.

\section{Conclusions}

Time-resolved thermal dissociation experiments, implemented with the BIRD technique and FT-ICR/MS, have been performed on a series of gaseous protonated and deprotonated protein-carbohydrate complexes produced by nonspecific interactions during the nanoES process. The results of this study have provided new insight into the nature of the intermolecular interactions in nonspecific protein-carbohydrate complexes in the gas phase. Over the range of temperatures investigated, the complexes were found to dissociate exclusively by the loss of the carbohydrate in its neutral form. Kinetic data measured for the dissociation of the 1:1 complexes containing a mono- or disaccharide suggest that multiple kinetically distinct complex structures are produced by nanoES. This result is consistent with the carbohydrates binding at multiple sites on the proteins in the gas phase. In contrast, kinetic data measured for the 1:1 complexes consisting of a tri- or tetrasaccharide suggest that the gaseous proteins have a single preferred carbohydrate binding site or multiple equivalent binding sites. Analysis of the kinetic data for the dissociation of several 1:2 protein-carbohydrate complexes suggests that Ubq presents a single preferred trisaccharide binding site in the gas phase, whereas CA offers multiple equivalent, but dependent, sites of interaction.

Arrhenius activation parameters were determined for the dissociation of a series of 1:1 complexes of CA with structurally related trisaccharides. Compelling evidence that neutral intermolecular hydrogen bonds contribute to the stability of the complexes, at least at certain charge states, was obtained. Surprisingly, the energetic stability of the complexes was found to be insensitive to the structure of the protein suggesting that the carbohydrates are able to form energetically equivalent interactions with the various functional groups presented by the protein or that binding occurs preferentially with the protein backbone. Although the protein structure does not influence the magnitude of the dissociation $E_{a}$ it can significantly influence the magnitude of $\Delta S^{\ddagger}$ (or $A$ factors). The energetic stability of a given protein-trisaccharide complex was found to be sensitive to its charge state, with $E_{a}$ initially increasing and then decreasing with increasing charge. It is proposed that both ionic and neutral hydrogen bonds 
are responsible for stabilizing nonspecific protein-carbohydrate complexes in the gas phase and that the relative contribution of neutral and ionic interactions is strongly influenced by charge state, with neutral interactions dominating at low charge states and ionic interactions dominating at high charge states.

\section{Acknowledgments}

The authors thank D. R. Bundle for generously providing several of the carbohydrates used in this study. Financial support was provided by the Natural Sciences and Engineering Research Council of Canada.

\section{References}

1. Smith, D. L.; Zhang, Z. Probing Noncovalent Structural Features of Proteins by Mass Spectrometry. Mass Spectrom. Rev. 1994, 13, 411-429.

2. Smith, R. D.; Bruce, J. E.; Wu, Q.; Lei, Q. P. New Mass Spectrometric Methods for the Study of Noncovalent Associations of Biopolymers. Chem. Soc. Rev. 1997, 26, 191-202.

3. Loo, J. A. Electrospray Ionization Mass Spectrometry: A Technology for Studying Noncovalent Macromolecular Complexes. Int. J. Mass Spectrom. 2000, 200, 175-186.

4. Hofstadler, S. A.; Griffey, R. H. Analysis of Noncovalent Complexes of DNA and RNA by Mass Spectrometry. Chem. Rev. 2001, 101, 377-390.

5. Daniel, J. M.; Friess, S. D.; Rajagopalan, S.; Wendt, S.; Zenobi, R. Quantitative Determination of Noncovalent Binding Interactions Using Soft Ionization Mass Spectrometry. Int. J. Mass Spectrom. 2002, 216, 1-27.

6. Heck, A. J. R.; van den Heuvel, R. H. H. Investigation of Intact Protein Complexes by Mass Spectrometry. Mass Spectrom. Rev. 2004, 23, 368-389.

7. Li, Y. T.; Hsieh, Y. L.; Henion, J. D.; Senko, M. W.; McLafferty, F. W.; Ganem, B. Mass-Spectrometric Studies on Noncovalent Dimers of Leucine-Zipper Peptides. J. Am. Chem. Soc. 1993, 115, 8409-8413.

8. Robinson, C. V.; Chung, E. W.; Kragelund, B. B.; Knudsen, J.; Aplin, R. T.; Poulsen, F. M.; Dobson, C. M. Probing the Nature of Noncovalent Interactions by Mass Spectrometry. A Study of Protein-CoA Ligand Binding and Assembly. J. Am. Chem. Soc. 1996, 118, 8646-8653.

9. Wu, Q.; Gao, J.; Joseph-McCarthy, D.; Sigal, G. B.; Bruce, J. E.; Whitesides, G. M.; Smith, R. D. Carbonic Anhydrase-Inhibitor Binding: From Solution to the Gas Phase. J. Am. Chem. Soc. 1997, 119, 1157-1158.

10. Kitova, E. N.; Bundle, D. R.; Klassen, J. S. Thermal Dissociation of Protein-Oligosaccharide Complexes in the Gas Phase: Mapping the Intrinsic Intermolecular Interactions. J. Am. Chem. Soc. 2002, 124, 5902-5913.

11. Kitova, E. N.; Bundle, D. R.; Klassen, J. S. Evidence for the Preservation of Specific Intermolecular Interactions in Gaseous Protein-Oligosaccharide Complexes J. Am. Chem. Soc. 2002, 124, 9340-9341.

12. Felitsyn, N; Peschke, M.; Kebarle, P. Origin and Number of Charges Observed on Multiply Protonated Native Proteins Produced by ESI. Int. J. Mass Spectrom. 2002, 219, 39-62.

13. Carpenter, J. F.; Crowe, J. H. An Infrared Spectroscopic Study of the Interactions of Carbohydrates With Dried Proteins. Biochemistry 1989, 28, 3916-3922.

14. Murray, B. S.; Liang, H.-J. Evidence for Conformational Stabilization of Beta-Lactoglobulin When Dried With Trehalose. Langmuir 2000, 16, 6061-6063.
15. Wang, W.; Kitova, E. N.; Klassen, J. S. Bioactive Recognition Sites May Not Be Energetically Preferred in Protein-Carbohydrate Complexes in the Gas Phase. J. Am. Soc. Chem. 2003, 125, 13630-13631.

16. Wang, W.; Kitova, E. N.; Klassen, J. S. Nonspecific ProteinCarbohydrate Complexes Produced by Nanoelectrospray Ionization. Factors Influencing Their Formation and Stability. Anal. Chem. 2005, 77, 3060-3071.

17. Wang, W.; Kitova, E. N.; Klassen, J. S. Influence of Solution and Gas Phase Processes on Protein-Carbohydrate Binding Affinities Determined by Nanoelectrospray Fourier Transform Ion Cyclotron Resonance Mass Spectrometry. Anal. Chem. 2003, 75, 4945-4955.

18. Felitsyn, N; Kitova, E. N.; Klassen, J. S. Thermal Decomposition of a Gaseous Multiprotein Complex Studied by Blackbody Infrared Radiative Dissociation. Investigating the Origin of the Asymmetric Dissociation Behavior. Anal. Chem. 2001, 73, 4647-4661.

19. Peschke, M.; Blades, A.; Kebarle, P. Charged States of Proteins. Reactions of Doubly Protonated Alkyldiamines With $\mathrm{NH}_{3}$ : Solvation or Deprotonation. Extension of Two Proton Cases to Multiply Protonated Globular Proteins Observed in the Gas Phase. J. Am. Chem. Soc. 2002, 124, 11519-11530.

20. Hunter, E. P. L.; Lias, S. G. Evaluated Gas Phase Basicities and Proton Affinities of Molecules: An Update. J. Phys. Chem. Ref. Data. 1998, 27, 413-656.

21. Dunbar, R. C.; McMahon, T. B. Activation of Unimolecular Reactions by Ambient Blackbody Radiation. Science 1998, 279, 194-197.

22. Price, W. D.; Williams, E. R. Activation of Peptide Ions by Blackbody Radiation: Factors That Lead to Dissociation Kinetics in the Rapid Energy Exchange Limit. J. Phys. Chem. A 1997, 101, 8844-8852.

23. Price, W. D.; Williams, E. R. Binding Energies of the ProtonBound Amino Acid Dimers Gly · Gly, Ala · Ala, Gly · Ala, and Lys $\cdot$ Lys Measured by Blackbody Infrared Radiative Dissociation. J. Phys. Chem. B 1997, 101, 664-673.

24. Clemmer, D. E.; Hudgins, R. R.; Jarrold, M. F. Naked Protein Conformations-Cytochrome-c in the Gas-Phase. J. Am. Chem. Soc. 1995, 117, 10141-10142.

25. Shelimov, K. B.; Jarrold, M. F. "Denaturation" and Refolding of Cytochrome c In Vacuo. J. Am. Chem. Soc. 1996, 118, 10313-10314.

26. Shelimov, K. B.; Clemmer, D. E.; Hudgins, R. R.; Jarrold, M. F. Protein Structure In Vacuo: Gas-Phase Confirmations of BPTI and Cytochrome c. J. Am. Chem. Soc. 1997, 119, 2240-2248.

27. Fye, J. L.; Woenckhaus, J.; Jarrold, M. F. Hydration of Folded and Unfolded Gas-Phase Proteins: Saturation of Cytochrome c and Apomyoglobin. J. Am. Chem. Soc. 1998, 120, 1327-1328.

28. Li, J.; Taraszka, J. A.; Counterman, A. E.; Clemmer, D. E. Influence of Solvent Composition and Capillary Temperature on the Conformations of Electrosprayed Ions: Unfolding of Compact Ubiquitin Conformers From Pseudonative and Denatured Solutions. Int. J. Mass Spectrom. 1999, 185/186/187, $37-47$.

29. Mao, Y.; Ratner, M. A.; Jarrold, M. F. Molecular Dynamics Simulations of the Charge-Induced Unfolding and Refolding of Unsolvated Cytochrome c. J. Phys. Chem. B. 1999, 103, 10017-10021.

30. Meot-Ner, M. The Ionic Hydrogen Bond and Ion Solvation. 2. Solvation of Onium Ions By One to Seven Water Molecules. Relations Between Monomolecular, Specific, and Bulk Hydrogen. J. Am. Chem. Soc. 1984, 106, 1265-1272.

31. Meot-Ner, M. Ionic Hydrogen Bond and Ion Solvation. 6. Interaction Energies of the Acetate Ion With Organic Molecules. Comparison of $\mathrm{CH}_{3} \mathrm{COO}^{-}$with $\mathrm{Cl}^{-}, \mathrm{CN}^{-}$, and $\mathrm{SH}^{-}$. J. Am. Chem. Soc. 1988, 110, 3854-3858. 